\title{
Composición, distribución y abundancia estacional del macroplancton de la bahía de Valparaíso
}

\author{
Sergio Palma G. y Sergio Rosales G. \\ Escuela de Ciencias del Mar \\ Universidad Católica de Valparaíso \\ Casilla 1020, Valparaíso, Chile
}

\begin{abstract}
Resumen. Se describe la composición específica y distribución espacio-temporal durante un ciclo anual del macroplancton recolectado al interior de la bahía de Valparaíso, entre junio de 1990 y agosto de 1991. Se identificaron 45 especies zooplanctónicas: 17 hidromedusas, 12 sifonóforos, 4 ctenóforos, 10 quetognatos y 2 salpas. El plancton de la bahía estuvo caracterizado por seis especies dominantes que alcanzaron el 92\% de la densidad total: Sagitta enflata, S. bierii, Muggiaea atlantica, Phialidium spp., Obelia spp., y Thalia democratica. La especie más frecuente y abundante a través de todo el año fue $S$. enflata, que representó el $46 \%$ del total del macroplancton.

Las fluctuaciones estacionales del macroplancton estuvieron intluenciadas por los cambios de temperatura superficial, especialmente en primavera y verano, cuando se registraron agregaciones masivas de algunas especies planctónicas. En agosto de 1991 se detectaron cambios importantes en la densidad y estabilidad de la columna de agua, asociados al incremento en la abundancia de S. enflata.
\end{abstract}

Palabras claves: macroplancton, composición, distribución estacional.

\section{Composition, distribution and seasonal abundance of macroplankton in Valparaíso Bay}

\begin{abstract}
The species compositions and time-space distribution of macrozooplankton collected within the Bay of Valparaíso is described over an annual cycle between June 1990 and August 1991. Forty five species were identified: 17 Hydromedusae, 12 Siphonophora, 4 Ctenophora, 10 Chaetognatha and 2 Salpidae. The following six species dominated the plankton (92\%): Sagitta enflata, S. bierii, Muggiaea atlantica, Phialidium spp., Obelia spp. and Thalia democratica. The most abundant and frequent species was $S$. enflata representing $46 \%$ of total macroplankton.

Seasonal fluctuation of the macrozooplankton was affected by changes in sea surface temperature, during the spring and summer season, when some species showed massive aggregations. S. enflata abundance increased in August 1991, this could be associated to important changes in density and stability of the water column.
\end{abstract}

Key words: macroplankton, species composition, seasonal distribution.

\section{INTRODUCCION}

La dinámica de las aguas interiores de la bahía de Valparaíso está determinada por la presencia de aguas subantárticas de la corriente de Humboldt, está afectada durante el invierno por aportes continentales del río Aconcagua, y en primavera y verano, por el influjo de aguas ecuatoriales subsuperficiales provenientes de procesos de surgencia ocurridos frente a Punta Curaumilla (Pizarro, 1976; Avaria et al., 1989). Esta bahía se caracteriza, además, porque tie- ne una estrecha plataforma continental y posee características geográficas e hidrográficas particulares, desarrollándose en ella una variedad de actividades antropogénicas.

Se ha visto que en zonas costeras, el zooplancton está influenciado por las características hidrográficas locales y sus patrones de distribución siguen, en general, la dinámica de las aguas costems (Raymont, 1983). El macroplancton constituye un componente importante del zooplancton, debido a su rol en la tra- 
ma trófica marina como consumidor secundario. Entre sus principales componentes destacan diversos predadores, como hidromedusas, sifonóforos, ctenóforos y quetognatos, cuyos efectos pueden ser importantes en el mantenimiento de las comunidades biológicas superiores en una zona determinada.

Se ha observado que diversos carnívoros planctónicos gelatinosos, como medusas, sifonóforos y ctenóforos, son importantes predadores de larvas de peces o competidores de éstos por el alimento (Purcell, 1985). Por esta razón, es importante conocer el ciclo estacional del macroplancton gelatinoso en aguas de la bahía de Valparaíso, ya que en ésta ocurren procesos de desove de numerosas especies de peces, crustáceos y moluscos (Avaria et al., 1989; Bravo, 1993).

Si bien existen varios trabajos sobre el macroplancton en aguas adyacentes a la bahía de Valparaíso (Avaria et al., 1989; Kaiser, 1993; Palma, 1971, 1973, 1977, 1986, 1994; Palma y Meruane, 1975), se carece de antecedentes sobre la composición específica y las variaciones espaciotemporales que experimenta la biocenosis macroplanctónica en aguas interiores de la bahía.

Por otra parte, el conocimiento de la estructura comunitaria del macroplancton en aguas de la bahía, permitirá visualizar los cambios que puede experimentar el ecosistema frente a fluctuaciones del ambiente. Como también, frente a alteraciones causadas por procesos oceanográficos (mareas rojas, surgencia, fenómeno El Niño), o por el impacto que recibe de diversas actividades humanas (turismo, actividad pesquera, transporte marítimo, descargas domésticas e industriales).

\section{MATERIALES Y METODOS}

Durante el período comprendido entre junio de 1990 y agosto de 1991 se efectuaron 12 cruceros oceanográficos mensuales con el B/E «Tiberíades», en aguas interiores de la bahía de Valparaíso. En cada crucero se muestrearon nueve estaciones situadas frente a la costa. El límite exterior de la bahía fue delimitado alrededor de la isóbata de $100 \mathrm{~m}$ de profundidad (Fig.1).

En cada estación oceanográfica se realizaron pescas oblicuas de zooplancton desde cerca del fondo a la superficie; la profundidad de muestreo fue

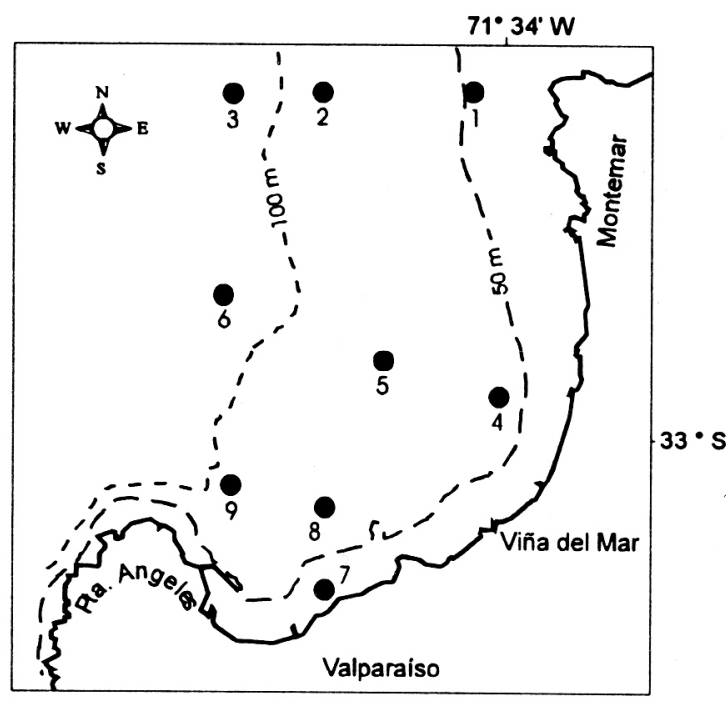

Figura 1. Posición geográfica de las estaciones de muestreo.

de $30 \mathrm{~m}$ para las estaciones más costeras y de $95 \mathrm{~m}$ para aquéllas situadas en el límite exterior de la bahía. Las pescas de plancton fueron hechas durante el día y se efectuaron con una red Bongo de $60 \mathrm{~cm}$ de diámetro y 350 micras de malla arrastrada a 2 nudos, provista de flujómetros TSK para la estimación del volumen de agua filtrado.

Las muestras zooplanctónicas fueron fijadas con formalina al $5 \%$ neutralizada con tetraborato de sodio. De las muestras obtenidas se extrajeron, identificaron y contaron los ejemplares de los siguientes taxa: hidromedusas, sifonóforos, ctenóforos, quetognatos y salpas. Debido a la estructura colonial de los sifonóforos, el recuento de individuos se efectuó únicamente para las especies del orden Calycophora considerando el número de nectóforos superiores, salvo cuando el número de los inferiores fue mayor, en cuyo caso se consideró este último como indicativo de su densidad.

La distribución estacional del macroplancton se analizó basado en las variaciones de abundancia relativa de las especies dominantes, considerando como tales aquéllas que constituyeron más del $5 \%$ del total de individuos por crucero (Bodenheimer, 1955), en a lo menos 2 de los 12 cruceros realizados. La abundancia o densidad específica fue estandarizada y expresada en número de individuos/1000 $\mathrm{m}^{3}$ de agua de mar. La representación gráfica de la densidad de 
plancton se realizó en base a la escala métrica $\log ^{2}$ que permite determinar clases de abundancia con valores equidistantes (Frontier, 1980).

De acuerdo a la función de la diversidad de Shannon-Weaver, se calculó el índice de uniformidad de Pielou para cada muestra y crucero oceanográfico. También, se estimó el grado de asociación entre especies mediante el índice de similitud biocenótica de Winer, utilizándose como criterio para incluir una especie en algún grupo determinado un nivel superior al $80 \%$ de coexistencia. Además, con el índice de subreposición de Horn se agruparon las muestras que tenían un grado de jerarquización superior al $80 \%$, donde el grupo de especies importantes mantiene la misma proposición de abundancia, contribuyendo de manera similar a la estimación de la diversidad específica (Pielou, 1966; Sáiz, 1980).

Para la caracterización hidrográfica de la aguas de la bahía se utilizaron botellas Niskin, provistas de termómetros de inversión. En cada estación de muestreo se tomaron muestras de la columna de agua para determinar la salinidad y registrar la temperatura in situ a las profundidades estándares de $0,5,10,25,50$ y 75 metros, según la profundidad de cada estación oceanográfica.

Con los datos de temperatura y salinidad obtenidos in situ se calculó la densidad y estabilidad de la columna de agua. La estabilidad se calculó en base a la siguiente expresión (Pond y Pickard, 1978):

$$
E=-\frac{1}{\bar{\rho}} \frac{\partial \sigma_{1}}{\partial z}
$$

donde $\sigma_{t}$ es la densidad del agua de mar referida a la superficie, $z$ la profundidad y $\rho$ la densidad media de la columna de agua.

Dado que en las estaciones de muestreo la profundidad de la columna de agua fue inferior a 100 $\mathrm{m}$, el efecto de la presión sobre la densidad del agua es despreciable; por lo tanto, se utilizó sigma-t promedio $\left(\bar{\sigma}_{t}\right)$ en vez de la densidad media $(\bar{\rho})$ de la columna de agua.

Además, para la descripción de las características hidrográficas de la zona de estudio, se consideraron las señales históricas anuales (enero 1961 a diciembre de 1991) y los promedios mensuales (enero 1990 a diciembre 1991) de temperatura superficial del mar (TSM), índice de surgencia (IS) e índi- ce de turbulencia (IT) calculados por Rosales y Balbontín (1994), a partir de las mediciones diarias de TSM en Montemar, y de dirección y magnitud del viento registrados en el Faro de Punta Angeles. El índice de surgencia que expresa el transporte de agua perpendicular a la costa por $1000 \mathrm{~m}$ lineales de ésta fue calculado siguiendo la metodología propuesta por Bakun $(1973 ; 1975)$. Los valores positivos indican el transporte de agua fuera de la costa y el ascenso de aguas más profundas en la costa. El índice de turbulencia fue calculado según Elsberry y Garwood (1978) y se expresó en $\mathrm{m}^{3} / \mathrm{s}^{3}$.

Para analizar las relaciones existentes entre las especies dominantes y las variables ambientales se utilizó el análisis discriminante y el análisis de correlación de Pearson. Para disminuir la varianza, en la correlación se aplicó la transformación $\ln (\mathrm{x}+1)$ a las densidades medias de cada especie.

\section{RESULTADOS}

\section{Caracterización oceanográfica del área de estudio}

Las mediciones hidrográficas efectuadas durante el desarrollo de esta investigación permitieron establecer la existencia de un ciclo anual de temperatura, donde los valores promedios mensuales fueron bastante parejos a lo largo del año, fluctuando entre 11,51 y $13,10 \mathrm{C}^{\circ}$, para invierno y verano respectivamente. En invierno, el rango de variación entre los valores superficiales y de fondo de la columna de agua fue pequeño, mientras que en primavera y verano fue mucho más alto. Este ciclo estacional fue más notorio en las aguas superficiales, que mostraron fluctuaciones más marcadas a lo largo del año por efecto de los cambios en la intensidad de luz (Fig.2a).

Los valores de salinidad fueron muy parejos a lo largo del año, con excepción del período invernal en que se observó un mayor rango de variabilidad espacial. particularmente enjulio y agosto de 1991 cuando se registraron valores superficiales inferiores a 34 psu en varias estaciones de la bahía (Fig. 2b). La distribución mensual de la densidad en la columna de agua (sigma-t), fue muy semejante a la distribución de salinidad (Fig. 2c). No obstante, las variaciones de densidad estuvieron más influenciadas por las variaciones de temperatura $(\mathrm{r}=0,84)$, que de salinidad $(\mathrm{r}=0,78)$. 

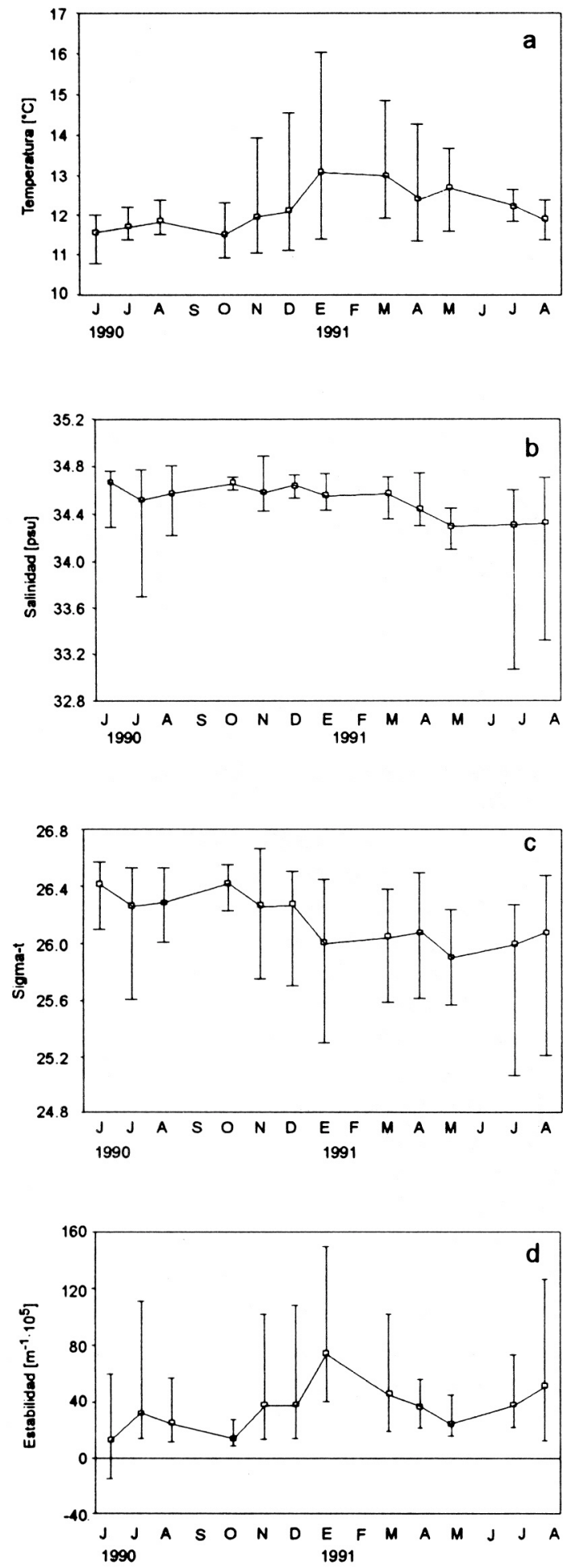

Figura 2. Rangos de variabilidad y valores promedios mensuales en la columna de agua: a) temperatura, b) salinidad, c) densidad y d) estabilidad de la columna.
El efecto de la interacción entre temperatura y salinidad de la columna de agua mostró una fluctuación mensual de estabilidad, con máximos estacionales que se incrementaron de primavera a verano (Fig. 2d). Sin embargo, en agosto de 1991 se observó un incremento y una mayor variabilidad en la estabilidad de la columna, que tuvo diferencias de $24 \times 10^{5} \mathrm{~m}^{-1}$ entre los valores mínimos y máximos. Cabe destacar que el máximo estimado para agosto de $1991\left(125 \times 10^{5} \mathrm{~m}^{-1}\right)$ fue muy cercano al máximo calculado para enero de ese mismo año $\left(149 \times 10^{5}\right.$ $\left.\mathrm{m}^{-1}\right)$.

De acuerdo con la señal histórica anual de TSM con los datos registrados frente a Montemar estimada para el período 1961-1991 (Rosales y Balbontín, 1994), se confirma la existencia de un ciclo anual de temperatura superficial en aguas de la bahía, caracterizado por mínimos registrados a fines de invierno y principios de primavera, y máximos en verano (Fig. 3a).

Al comparar los promedios mensuales de temperatura superficial entre 1990 y 1991, se observó que en este último año los valores fueron generalmente más elevados respecto a 1990, siendo un año relativamente más cálido, especialmente en los meses de invierno (Fig. 3a). En 1991 los valores promedios mensuales fueron incluso más altos que la señal histórica anual de temperatura superficial.

Durante 1990 se observaron valores positivos del índice de surgencia (IS) a lo largo del año, los cuales sólo a fines de primavera superaron los $500 \mathrm{~m} 3 /$ s*1000 m de costa (Fig. 3b). En cambio en 1991, se observaron mayores valores del IS a lo largo de casi todo el año, con excepción de junio en que se obtuvieron valores negativos, que indicarían procesos de hundimiento. Comparando los datos de estos años con la señal histórica anual estimada para el período 1961-1991, se observó que en 1991, los valores promedios fueron muy similares a los mostrados por la señal anual y que los promedios de 1990 estuvieron por debajo de ésta (Fig. 3b).

El índice de turbulencia calculado para el período 1990-1991 presentó valores elevados en primavera y verano, y valores bajos en otoño e invierno (Fig. 3c). Comparando los promedios mensuales del índice de turbulencia para ambos años, los valores siempre fueron superiores a los de 1990, a excepción del verano de ese año. Además, en 1991 los valores del índice estuvieron más cercanos a los valores correspondientes a la señal histórica anual 

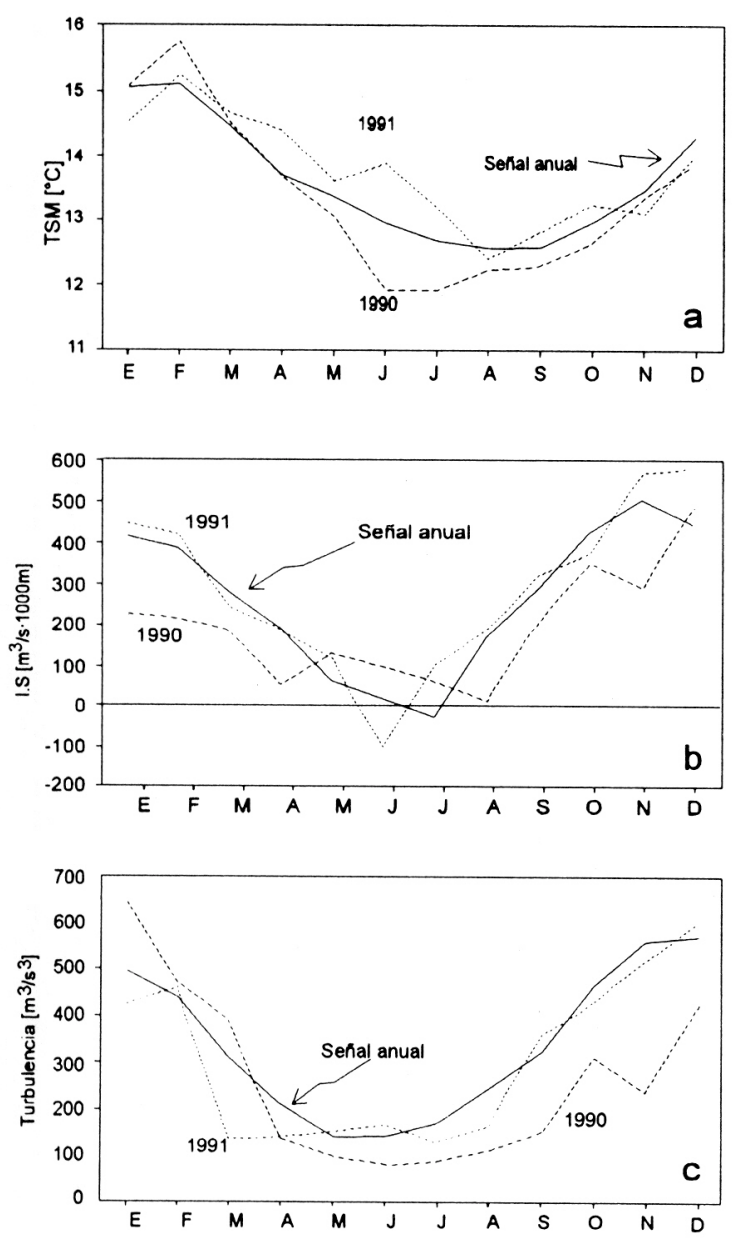

Figura 3. Promedios mensuales y señales históricas de: a) temperatura superficial del mar, b) índice de surgencia, y e) índice de turbulencia.

estimada para el período 1966-1991 (Fig. 3c).

\section{Composición específica y abundancia relativa} del macroplandon

Durante el estudio del ciclo anual de plancton se obtuvo un total de 107 muestras, identificándose 45 especies distribuidas en 17 especies de hidromedusas, 12 de sifonóforos, 4 de ctenóforos, 10 de quetognatos y 2 de salpas. De este último taxon se identificaron las formas sexuales (blastozoides) y asexuales (ozoides) de las especies identificadas.

La determinación específica de los taxa analizados se efectuó en base a la bibliografía especializada (Boltovskoy, 1981; Fagetti, 1958, 1958, 1973; Palma, 1971,1973, 1986; Palma y Kaiser, 1993).
El listado completo de las especies identificadas, con sus respectivas densidades medias mensuales Tabla 1 .

Durante el ciclo anual se encontró que el macroplancton de la bahía estuvo caracterizado por la presencia de sólo seis especies dominantes, las cuales fueron Muggiaea atlantica, Obelia spp., Phialidium spp., Sagitta bierii, S. enflata y Thalia democratica. En la Tabla 2 se indica el número de cruceros en que se cumplió el criterio de Bodenheimer (1955) y la frecuencia relativa promedio por especie.

Tabla 2. Especies dominantes en aguas de la bahía de Val paraíso.

\begin{tabular}{lcc}
\hline Especie & $\begin{array}{c}\text { Número de cruceros } \\
\text { con frecuencia } \\
\text { relativa mayor de 5\% }\end{array}$ & $\begin{array}{c}\text { Frecuencia } \\
\text { relativa } \\
\text { promedio }\end{array}$ \\
\hline Muggiaea atlantica & 7 & 29.39 \\
Obelia spp. & 5 & 10.67 \\
Phialidium spp. & 3 & 12.33 \\
Sagitta bierii & 7 & 14.96 \\
Sagitta enflata & 12 & 52.83 \\
Thalia democratica & 2 & 27.73 \\
\hline
\end{tabular}

A excepción de T. democratica, que se capturó sólo entre noviembre y marzo, las restantes especies se encontraron durante casi todo el año en el plancton.

\section{Distribución estacional del macroplancton}

La distribución del macroplancton en aguas interiores de la bahía presentó un ciclo estacional, caracterizado por máximas densidades en los meses de verano, con abundancias promedios de 2.542 ind./1000 $\mathrm{m}^{3}$ en enero de 1991 y mínimas en invierno, con promedios de 229 ind./1000 $\mathrm{m}^{3}$ en julio de 1990 (Fig. 4a). Este patrón de distribución fue alterado en invierno de 1991, cuando se produjo un fuerte aumento en la cantidad de plancton que alcanzó los 1.346 ind./l $000 \mathrm{~m}^{3}$ en agosto, correspondiente al incremento en la abundancia de Sagitta enflata, que se registró a partir de marzo de 1991 (Fig. 4b). Esta especie, por su elevada abundancia, es responsable de las mayores fluctuaciones del macroplancton en aguas de la bahía.

Las distintas especies macroplanctónicas presentaron marcadas fluctuaciones estacionales, especialmente las especies dominantes (Figs. 4a y 4b). La comunidad macroplanctónica no sólo experimentó cambios en su distribución temporal, sino que además en su distribución espacial al interior de la ba- 
Tabla 1. Densidades medias de las especies macroplanctónicas (ind./1000 $\left.\mathbf{m}^{3}\right) .(+)$ indica presencia en escasa cantidad.

\begin{tabular}{|c|c|c|c|c|c|c|c|c|c|c|c|c|}
\hline \multirow[b]{2}{*}{ ESPECIES } & \multicolumn{6}{|l|}{1990} & \multicolumn{6}{|l|}{1991} \\
\hline & JUN & JUL & AGO & OCT & NOV & DIC & ENE & MAR & ABR & MAY & JUL & $\overline{\mathrm{AGO}}$ \\
\hline $\begin{array}{l}\text { HIDROMEDUSAS } \\
\text { Sarsia eximia }\end{array}$ & & 8 & 11 & 32 & 9 & & & & & & & \\
\hline Euphysa aurata & & 2 & 6 & 244 & 34 & 280 & 424 & & & 2.4 & 34 & 34 \\
\hline Ectopleura dumortieri & & & & 4 & 4 & 16 & 31 & & & & & 8 \\
\hline Dipurena ophiogaster & & & & & 110 & & & & & & & \\
\hline Sminthea eurygaster & & & & & 2 & & 8 & & & & & \\
\hline Leuckartiara octona & & & & 9 & 3 & & & & & & & 0.8 \\
\hline Obelia spp. & & 5 & 129 & 1530 & 4467 & 317 & 155 & 335 & & 20 & & 117 \\
\hline Phialidium spp. & 7 & 3 & 21 & 1243 & 5243 & 429 & 370 & 676 & 2 & & 2 & 79 \\
\hline Liriope tetraphylla & & 3 & 20 & 13 & & & 244 & 420 & & & & \\
\hline Halicreas minimun & & & & & & & & 5 & & 1 & 1 & 6 \\
\hline Halitrephes maasi & & & & 26 & 1 & & & & & & & \\
\hline Aglaura hemistoma & & 2 & 2 & 2 & & & 109 & & & & & \\
\hline Solmundella bitentaculata & & & & 94 & 99 & 19 & 291 & 172 & 2 & & & \\
\hline Solmissus marshalli & & & & & & & & & + & & & \\
\hline Bougainvillia involuta & & & & 19 & & 3 & & & & & & \\
\hline Crossota brunnea & & & & & & & 43 & & & & & \\
\hline Cunina peregrina & & & & & & & + & & & & & \\
\hline SIFONOFOROS & & & & & & & & & & & & \\
\hline Agalma elegans & & + & & & & & & & + & & + & + \\
\hline Amphicaryon acaule & & & & & & 9.6 & 1.6 & & & 1.8 & & \\
\hline Rosacea cymbiformis & & + & & & & & & & & & & \\
\hline Rosacea plicata & & & & 1.1 & & & & & & & & \\
\hline Vogtia spinosa & & & & 5.4 & & & & & & & & \\
\hline Lensia meteori & & 1.4 & & & & & & & & & & \\
\hline Lensia subtilis & & & & & & & 5.2 & & & & & \\
\hline Muggiaea atlantica & 495 & 807 & 133 & 7048 & 4631 & 3665 & 2102 & 290 & 183 & 83 & 83 & 698 \\
\hline Eudoxoides spiralis & & & 9 & & & & 6 & & & & & \\
\hline Sphaeronectes gracilis & & & & 17 & 132 & 502 & 1812 & 789 & 31 & 33 & 29 & 40 \\
\hline Sphaeronectes fragilis & & & & 74 & & & & & & & & \\
\hline Abylopsis tetragona & & 4 & & & 1.6 & & & 0.8 & & 0.9 & & 0.8 \\
\hline CTENOFOROS & & & & & & & & & & & & \\
\hline Pleurobrachia pileus & & 14 & 2.2 & 612 & 325 & 89 & 27 & & 1 & 1 & 7 & 690 \\
\hline Mnemiopsis sp. & 21 & 28 & 0.7 & 16 & 122 & 193 & 113 & 179 & 8 & 67 & 7 & 2 \\
\hline Beroe cucumis & & & & & & & & & 1.8 & 1.9 & & \\
\hline Beroe sp. & & & & 10 & 7 & & & & & & & \\
\hline QUETOGNATOS & & & & & & & & & & & & \\
\hline Sagitta bierii & 1086 & 366 & 62 & 1049 & 1180 & 850 & 15830 & 335 & 1365 & 91 & 465 & 1005 \\
\hline Sagitta enflata & 1340 & 2303 & 1100 & 1118 & 6114 & 3506 & 14878 & 4451 & 8633 & 3897 & 15747 & 18828 \\
\hline Sagitta decipiens & & & & & & + & & & & & & \\
\hline Sagitta lyra & & & & 44 & 7 & & & & & & 3 & 3 \\
\hline Sagitta maxima & 2 & & & 63 & & & & & & & & \\
\hline Sagitta minima & 15 & 27 & & & & & & & & 81 & 61 & \\
\hline Sagitta planctonis & & & & 68 & & & & & & & & \\
\hline Eukronia hamata & 79 & 39 & & 2283 & 4 & 31 & & 8 & 12 & & 31 & 4 \\
\hline Krohnitta subtilis & 153 & 49 & & 1039 & 18 & 64 & 423 & 55 & 98 & & 12 & 18 \\
\hline Pterosagitta draco & & & & & & 3 & & & & & 3 & \\
\hline SALPAS & & & & & & & & & & & & \\
\hline Pegea confoederata & & & & & & & 9 & & & & & \\
\hline Thalia democratica & & & & & 255 & 3158 & 15281 & 14 & & & & \\
\hline
\end{tabular}


a

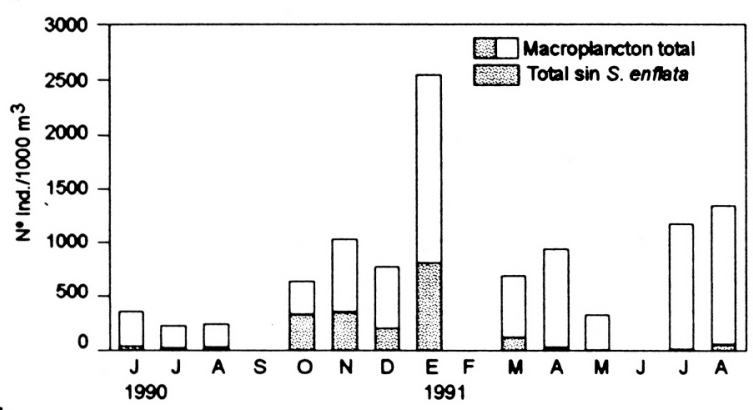

b

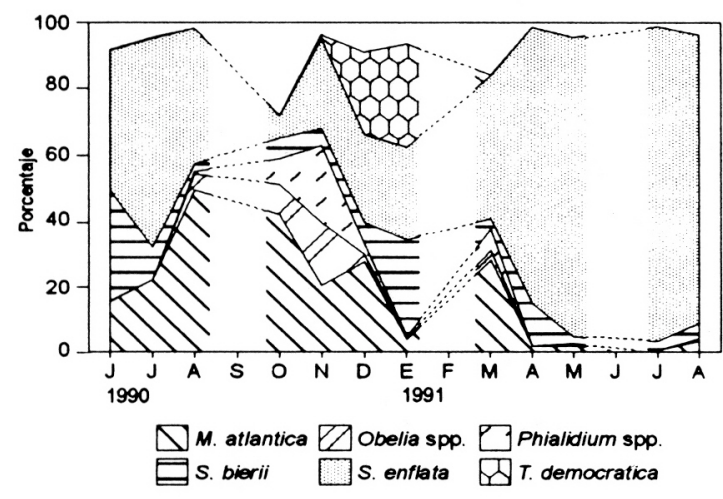

Figura 4. a) Distribución de la abundancia media del macroplancton capturado entre junio de 1990 y agosto de 1991, con y sin Sagina enflata, y b) fluctuaciones estacionales de la abundancia relativa de las especies dominantes. Las bandas blancas corresponden a meses en que no hubo muestreo.

hía, lo cual se pudo apreciar más claramente en la distribución de las especies dominantes (Figs. 5 a 7).

\section{Hidromedusas}

Las hidromedusas se presentaron a lo largo de todo el año en la bahía, determinándose su mayor abundancia de octubre a marzo, con bajas cantidades de individuos de abril ajulio. De las 18 especies identificadas, las más abundantes y frecuentes fueron Phialidium spp. y Obelia spp., ambos géneros comprenden un número elevado de especies, las cuales no han sido claramente identificadas. Debido al carácter meroplanctónico de estos especímenes, se encontraron formando densas agregaciones en octubre y noviembre (Figs. 4b y 5).

Las mayores agregaciones de Phialidium spp. se registraron en noviembre, cuando se obtuvieron densidades medias de 5.243 ind./1000 m³ , con un máximo de 16.384 ind./1000 $\mathrm{m}^{3}$ en la estación 8 . Al igual que esta especie, Obelia spp. también se recolectó abundantemente en noviembre, cuando se presentó en concentraciones medias de 4.467 ind./1000 $\mathrm{m}^{3}$, con máximos de 26.513 ind./1000 $\mathrm{m}^{3}$ en la estación 8 (Fig. 5). En cambio, las especies holoplanctónicas como Euphysa aurata, Ectopleura dumortieri, Phialella quadrata, Aglaura hemistoma y Solmundella bitentaculata, fueron más abundantes en verano. Las especies restantes fueron capturadas esporádicamente en aguas de la bahía (Tabla 1).

\section{Sifonóforos}

Los sifonóforos se encontraron durante todo el año en aguas de la bahía, presentando mayores abundancias en primavera y verano. La comunidad de sifonóforos estuvo constituida por 12 especies (Tabla 1), siendo Muggiaea atlantica la especie más abundante y frecuente durante todo el año, especialmente en primavera y verano (Fig. 4b y 6).

Las mayores agregaciones de $M$. atlantica se registraron en octubre, cuando alcanzó densidades medias de 7.048 ind./1000 $\mathrm{m}^{3}$, con un máximo de 13.548 ind./1000 $\mathrm{m}^{3}$ en la estación 5 , mientras que las menores densidades poblacionales se registraron de abril ajulio, con promedios iguales a 83 ind./1000 $\mathrm{m}^{3}$ (Fig. 6). Esta especie fue seguida en abundancia por Sphaeronectes gracilis con un 1,9\% del total, que sólo se encontró en forma importante en verano, presentando densidades medias de 1.812 ind./ $1000 \mathrm{~m}^{3}$ en enero. Las restantes especies se presentaron ocasionalmente y en escasa cantidad al interior de la bahía (Tabla 1).

\section{Ctenóforos}

Los ctenóforos se recolectaron durante todo el año, siendo más abundantes en primavera y verano. De las cuatro especies identificadas, Pleurobrachia pileus fue la más abundante con un $1 \%$ del total del macroplancton y se encontró principalmente de mediados de invierno a primavera. Los mayores valores de abundancia relativa se registraron en agosto de 1991, cuando se determinaron densidades medias de 690 ind./1000 m³ con máximos de 2.439 ind./ $1000 \mathrm{~m}^{3}$ en la estación 4. Le siguió en abundancia Mnemiopsis sp., que se presentó en mayor densidad en primavera y verano. Las dos especies representantes del género Beroe, fueron escasas y esporádicas (Tabla 1).

\section{Quetognatos}

Los quetognatos fueron los organismos 


\section{Phialidium spp.}
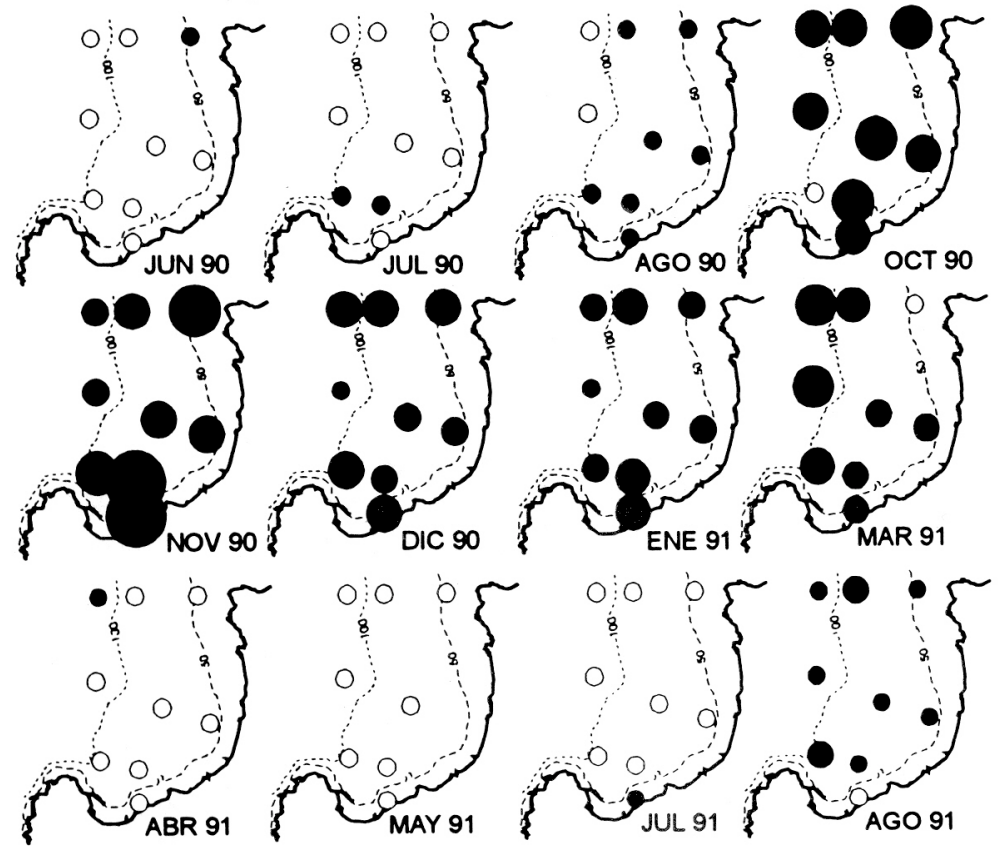

ind $.11000 \mathrm{~m}^{3}$

○ 0

- $1-65$

- $65-367$

Obelia spp.

$367-1386$
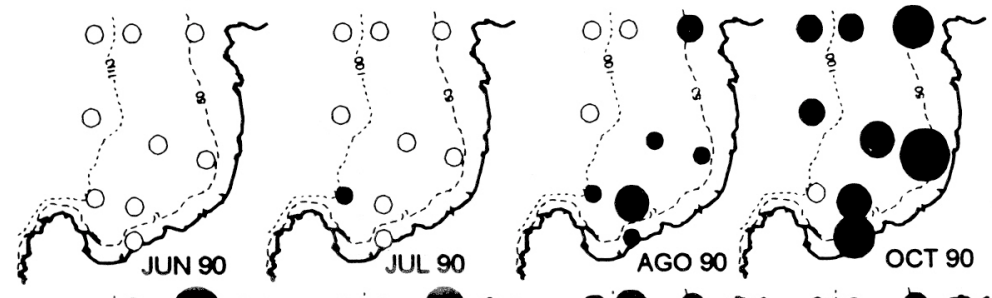

C $1386-4243$

$4243-11373$

$11373-27733$
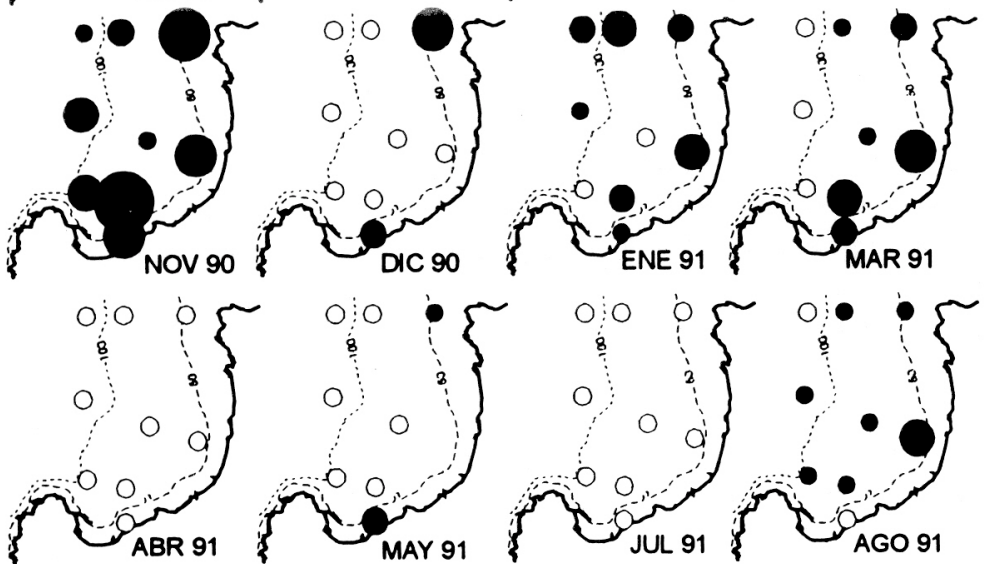

Figura 5. Distribución espacio-temporal de Phialidium spp. y Obelia spp. 


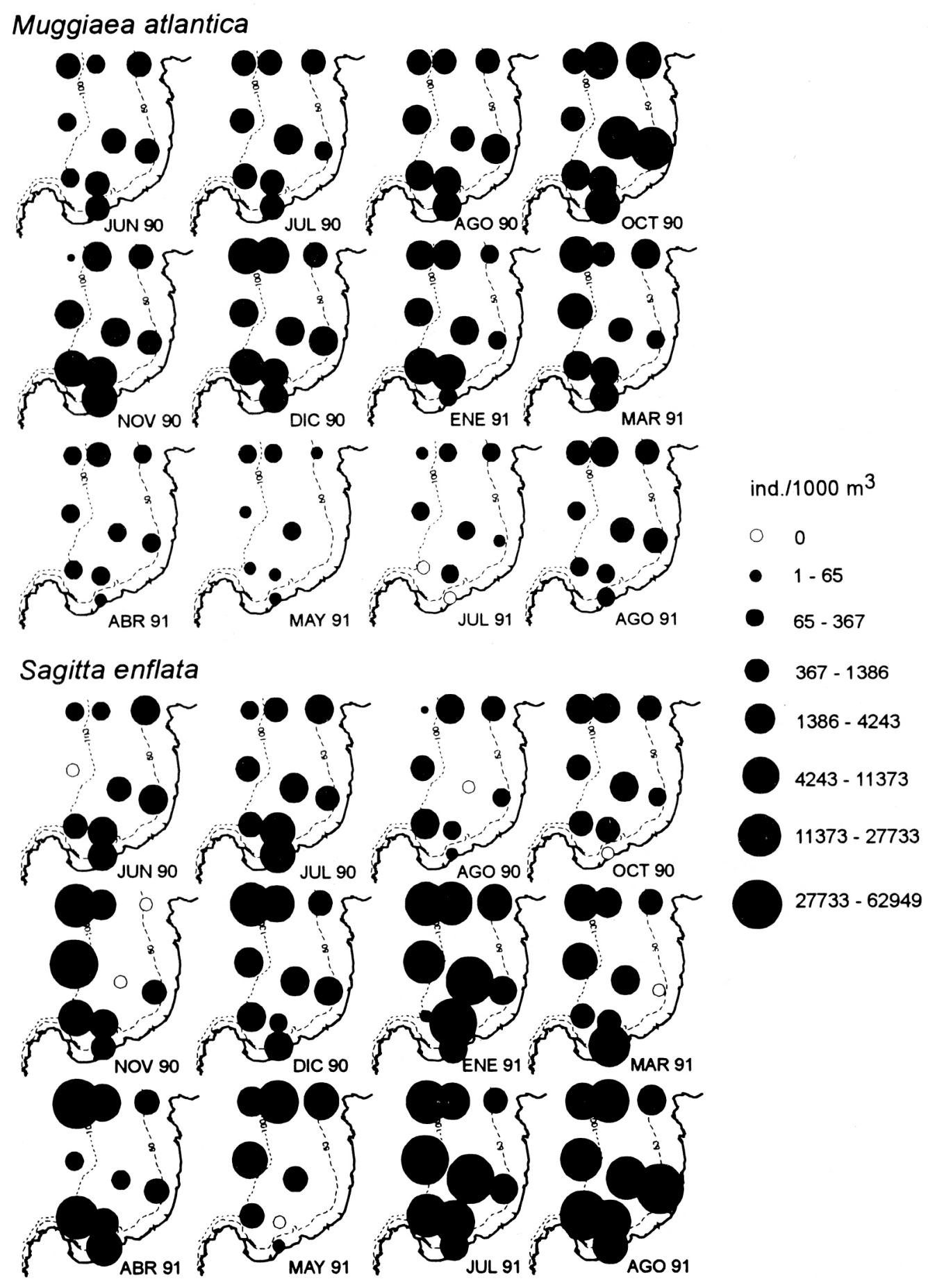

Figura 6. Distribución espacio-temporal de Muggiaea atlantica y Sagitta enflata. 


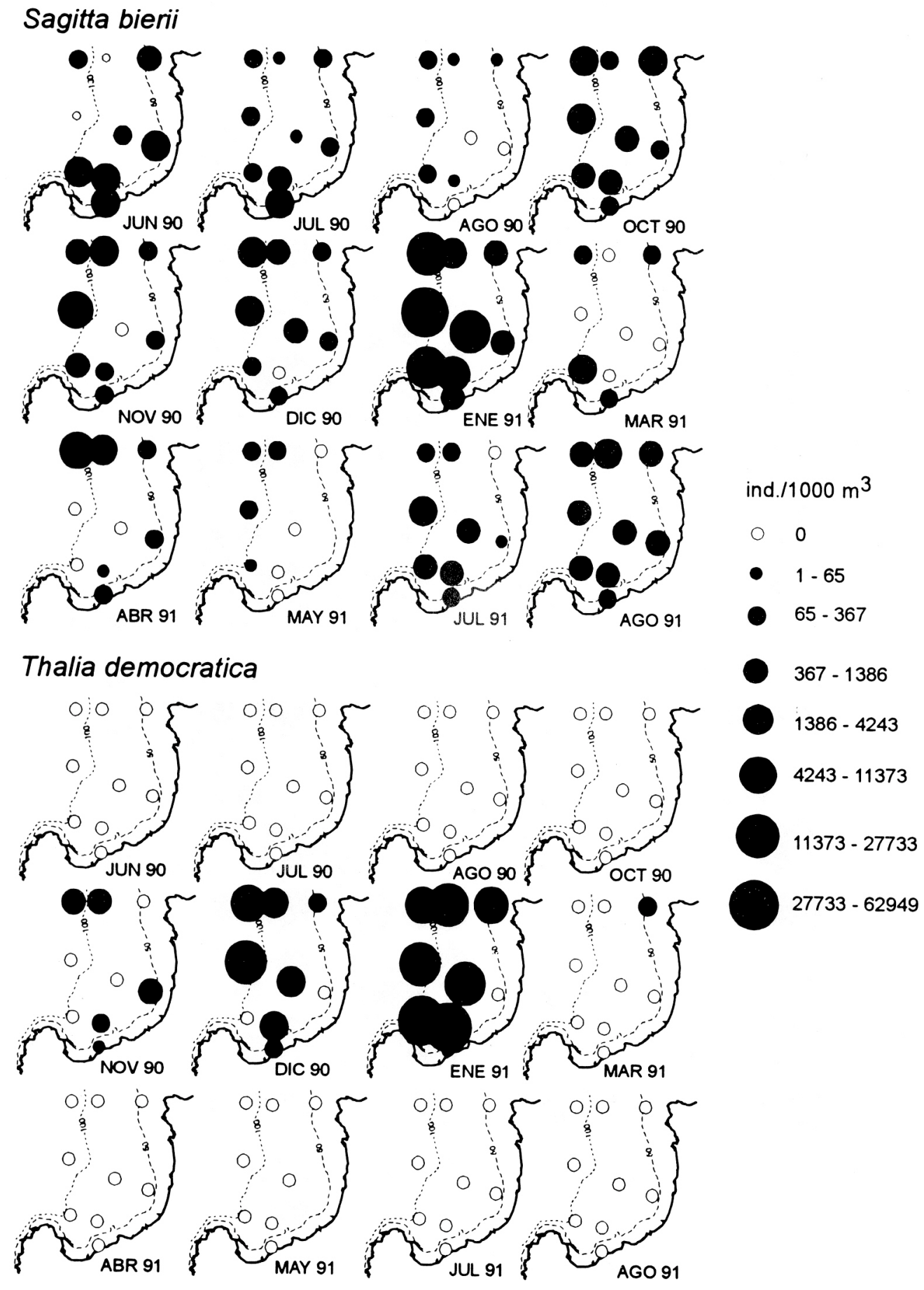

Figura 7. Distribución espacio-temporal de Sagitta bierii y Thalia democratica. 
planctónicos más abundantes y frecuentes en aguas interiores de la bahía. De las 10 especies identificadas (Tabla 1), Sagitta enflata y S. bierii fueron determinadas como especies dominantes. Sagitta enflata fue la especie predominante del plancton de la bahía durante todo el ciclo anual (Fig. 4b), sus poblaciones se presentaron formando densas agregaciones en primavera y verano, particularmente en enero de 1991 cuando se obtuvo un promedio de 14.878 ind./1000m ${ }^{3}$, con un máximo de 38.339 ind./1000 $\mathrm{m}^{3}$ en la estación 5 (Fig. 6). Sin embargo, en otoño e invierno de 1991 se notó un fuerte incremento en su abundancia, alcanzando un promedio de 18.828 ind./1000 $\mathrm{m}^{3}$ en agosto de 1991, que fue superior a los valores estimados para enero de 1991. Las menores densidades poblacionales se registraron en agosto 1990, con densidades medias de 1.100 ind./1000 $\mathrm{m}^{3}$.

La otra especie dominante de este taxon $S$. bierii, se encontró durante todo el año en concentraciones medias de alrededor de 1.000 ind./1000 $\mathrm{m}^{3}$. No obstante, en enero de 1991 se registró un notorio incremento de su densidad poblacional, determinándose densidades medias de 15.830 ind./ $1000 \mathrm{~m}^{3}$, capturándose un máximo de 71.515 ind./ $1000 \mathrm{~m}^{3}$ en la estación 6 (Fig. 7). De las nueve especies restantes, destacó la elevada frecuencia de Eukrohnia hamata y Krohnitta subtilis, que se presentaron con mayor abundancia en octubre. En esta misma época del año, se detectó un número importante de ejemplares correspondientes a Sagitta lyra, S. maxima y S. planctonis.

\section{Salpas}

Durante el período de estudio se detectó la presencia de dos especies de salpas: Thalia democratica y Pegea confoederata. A pesar que T. democratica se recolectó exclusivamente entre noviembre y marzo, por la gran abundancia en que se presentó en el plancton de la bahía en diciembre y enero, fue clasificada como especie dominante (Fig. 4b). Las mayores agregaciones de T. democratica se registraron en enero, cuando se determinaron concentraciones promedio de $15.281 \mathrm{ind} . / 1000 \mathrm{~m}^{3}$, detectándose un máximo de 53.394 ind./1000 $\mathrm{m}^{3}$ en la estación 8 (Fig. 7).

Las poblaciones de $T$. democratica estuvieron compuestas fundamentalmente por blastozoides, cuya abundancia mensual fluctuó entre un 93 y 98\% en relación al número de ozoides. Estas diferencias se producen debido al ciclo reproductivo de estos organismos, ya que cada blastozoide origina un solo oozoide, mientras que cada oozoide puede producir varias decenas de blastozoides. La otra especie de salpa, $P$. confoederata, estuvo representada por algunos blastozoides recolectados en enero de 1991.

\section{Estructura comunitaria del macroplancton}

Sobre la base de la información cuali y cuantitativa del macroplancton, se aplicaron diversos índices comubitarios para visualizar su estructura comunitaria en aguas de la bahía de Valparaíso.

\section{Análisis mensual}

El número de especies recolectadas mensualmente varió de 9 de junio a 26 en octubre de 1990 , obteniéndose la mayor riqueza específica en primavera y verano (Fig. 8a), cuando se identificaron varias especies que se encontraron en una sola oportunidad en la bahía (Tabla 1). Los valores de uniformidad específica «J» fluctuaron entre 0,093 y 0,634 siendo obtenidos en julio 1991 y diciembre 1990 respectivamente. En la mayor parte del período de estu-
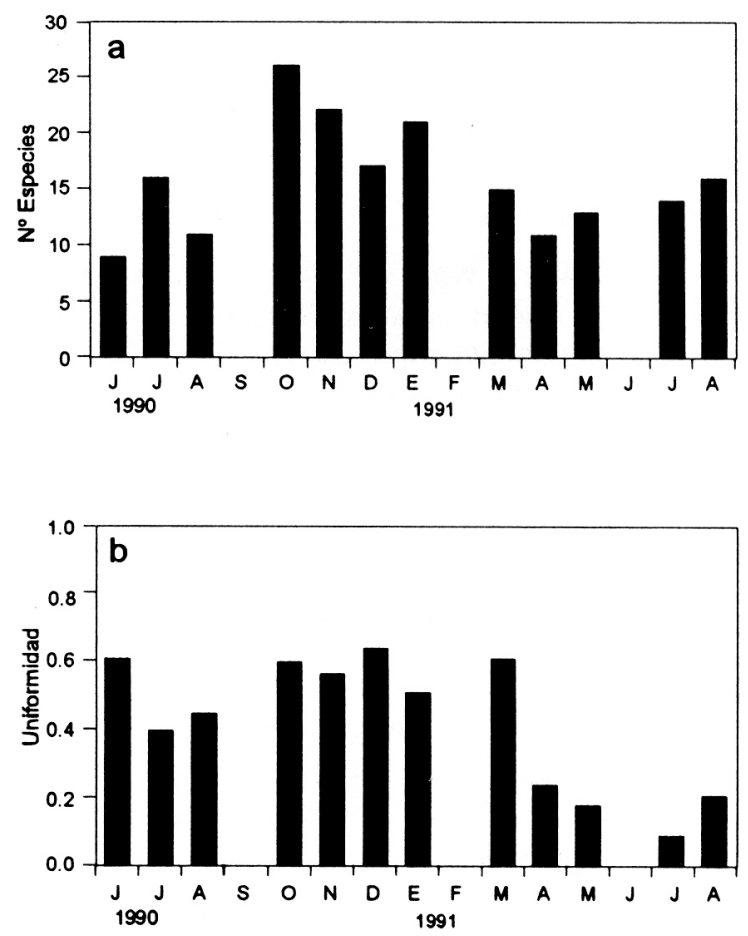

Figura 8. a) Número de especies macroplanctónicas presentes durante el ciclo anual; b) Indice de uniformidad calculado a partir del índice de diversidad de ShannonWeaver. 
dio, los valores mensuales de unifonnidad fueron iguales o superiores a 0,4 alcanzando sus máximos valores a fines de primavera; en cambio a partir de abril de 1991 se produjo un brusco descenso de la unifonnidad, observándose el valor mínimo en julio de 1991 (Fig. 8b).

Las muestras obtenidas en los distintos cruceros oceanográficos se agruparon de acuerdo al índice de sobreposición de Horn, encontrándose que al nivel del $65 \%$, la diversidad específica fue similar en todos los cruceros (Fig. 9). En este conjunto de cruceros, se detenninaron tres grupos con una similitud superior al 80\%: el Grupo 1 constituido por los de otoño e invierno; el Grupo 2 fonnado por los de verano; y el Grupo 3 por los de agosto y noviembre de 1990, y marzo de 1991. En la Tabla 3 se muestran las especies que aportaron más de 0,05 de similitud en promedio a la fonnación de cada grupo.

Tabla 3. Especies que aportaron más a la agrupación de los cruceros oceanográficos.

\begin{tabular}{lccc}
\hline Especie & Grupo 1 & Grupo 2 & Grupo 3 \\
\hline Obelia spp. & & & 0.056 \\
Muggiaea atlantica & & 0.114 & 0.338 \\
Sagitta bierii & & 0.101 & \\
Sagitta enflata & 0.730 & 0.270 & 0.374 \\
Thalia democratica & 0.266 & & \\
\hline
\end{tabular}

Las distintas especies identificadas durante el ciclo anual fueron asociadas de acuerdo al índice de Winer, encontrándose que al nivel del $80 \%$ se fonnaron cuatro grupos de especies coexistentes (Fig. 10). De éstos, se destacan dos grupos: en primer lugar el grupo 3 formado por 13 especies de escasa frecuencia anual que tuvieron en común su presencia en primavera; en segundo lugar, el grupo 4 formado por un conjunto de 11 especies de presencia estival, que comprende especies abundantes como $T$. democratica y $S$. bierii, y especies ocasionales. Con relación a las otras especies dominantes, $S$. enflata y $M$. atlantica, los resultados de este análisis indican la no coexistencia al $80 \%$ con otras especies macroplanctónicas.

\section{Análisis espacial}

Los valores de unifonnidad presentaron una alta variabilidad en las estaciones oceonográficas situadas al interior de la bahía (Fig. 11), detectándose generalmente valores superiores a 0,5 en el período de junio de 1990 a abril de 1991, estimándose en diciembre la mayor unifonnidad en la estación 7 (1= 0,829). A partir de mayo de 1991, se observó una baja generalizada en los valores de unifonnidad, particularmente enjulio y agosto, cuando se obtuvo una mayoría de valores inferiores a 0,5 (Fig. 11). Esta disminución registrada de mayo a agosto fue debida al incremento en la abundancia de S. enjlata en este mismo período.

Con el índice de Horn se agruparon las muestras de cada crucero, observándose que la estructurajerárquica del macroplancton no es unifonne al interior de la bahía. De invierno a principios de primavera se detenninaron dos grupos de estaciones asociadas en un $80 \%$ de similitud, uno fonnado por las estaciones costeras y otro por las situadas en el borde externo de la bahía (Fig. 11) Este esquema se vio modificado desde mediados de primavera a verano, cuando las estaciones del centro de la bahía se asociaron con estaciones costeras o del borde externo. A comienzos de otoño se detectaron nuevamente los dos grupos identificados en invierno de 1990, Sin embargo, a partir de mayo de 1991, comienza a observarse una mayor dominancia en la bahía, encontrándose en invierno una sola estructura jerárquica, que alcanza incluso una similitud de un $89 \%$ (Fig. 11).

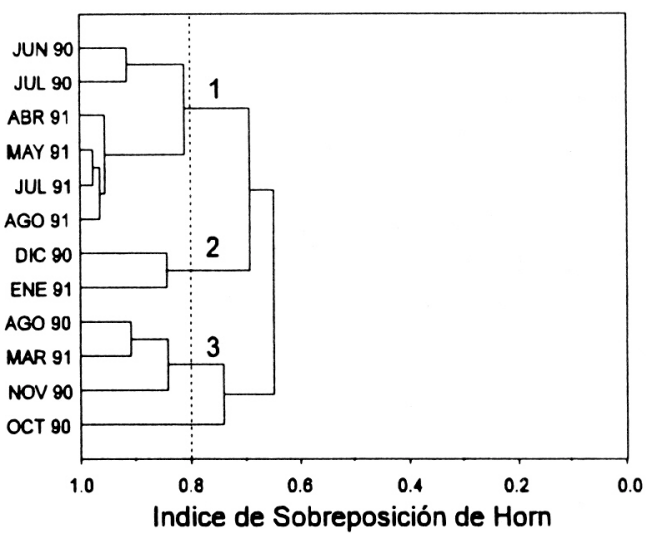

Figura 9. Cruceros oceanográficos agrupados con un criterio del $80 \%$ de similitud en su grado de jerarquización determinado mediante el índice de sobreposición de Horn. 


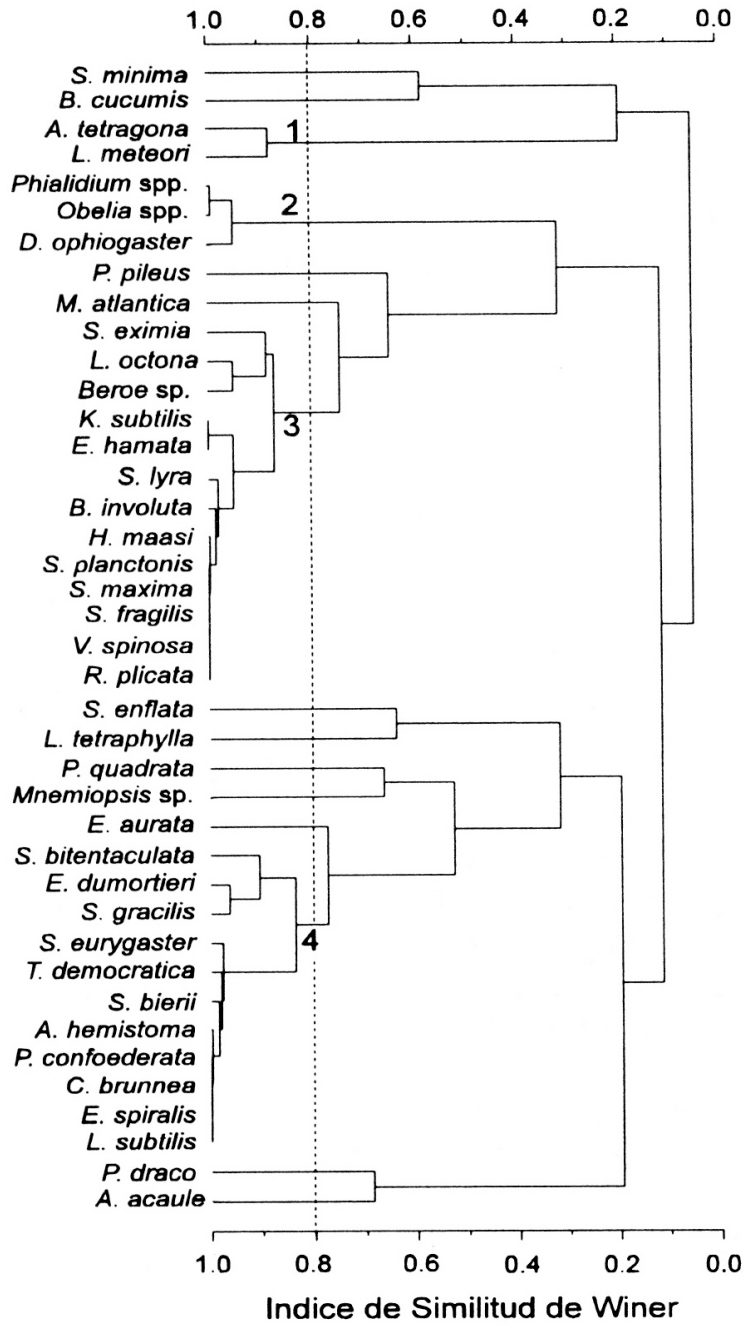

Figura 10. Especies zooplanctónicas agrupadas con un criterio del $80 \%$ de coexistencia según el índice de similitud biocenótica de Winer.

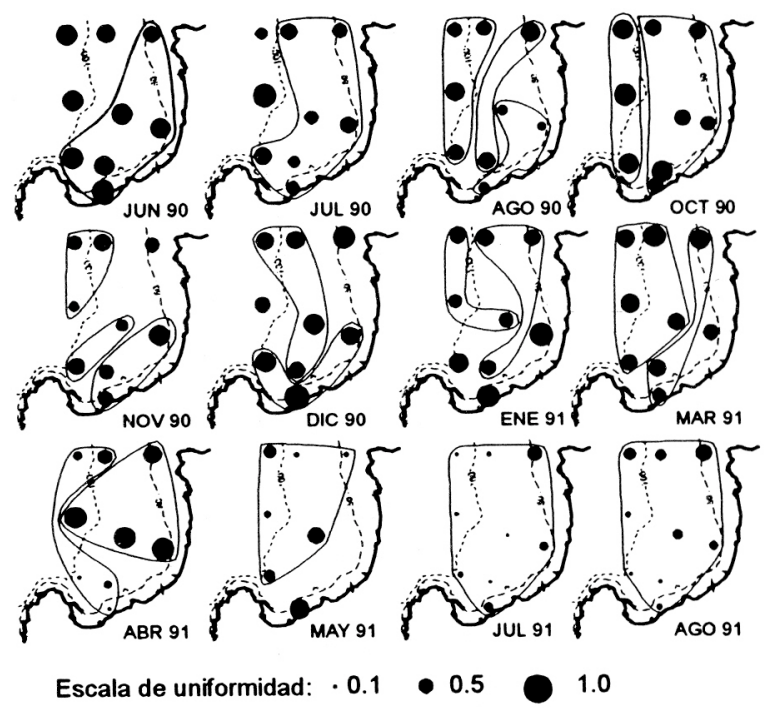

Figura 11. Distribución espacio-temporal del índice de uniformidad, indicando la agrupación de las muestras que tienen un $80 \%$ de similitud en su grado de jerarquización, determinado mediante el índice de sobreposición de Horn.

\section{Relaciones entre las especies y su medio ambiente}

De acuerdo a la agrupación mensual de los cruceros oceanográficos obtenida mediante el índice de Hom, se efectuó un análisis discriminante con las distintas variables ambientales consideradas en este estudio (índices de surgencia y turbulencia, temperatura, salinidad, sigma-t y estabilidad). Este análisis fue significativo (Wilk's Lambda $=0.0016016 ; \mathrm{F}_{(12.6)}=$ 12.40563 con P-valor <0.0028) y se encontró que la variabilidad de los parámetros ambientales fue se-

Tabla 4. Valores de correlación entre las especies dominantes y las variables ambientales. Con asterisco se indican los valores significativos al nivel de 0,05 .

\begin{tabular}{|c|c|c|c|c|c|c|}
\hline Especie & IS & IT & $\mathrm{T}$ & $S$ & $\sigma_{t}$ & $\mathrm{E}$ \\
\hline Muggiaea atlantica & $0,62 *$ & 0,56 & $-0,56$ & $0,79 *$ & $0,74 *$ & 0,12 \\
\hline Obelia spp. & $0,58 *$ & 0,56 & $-0,31$ & 0,36 & 0,36 & 0,19 \\
\hline Phialidium spp. & $0,72 *$ & $0,62 *$ & $-0,42$ & $0,58 *$ & 0,54 & 0,29 \\
\hline Sagitta bierii & $0,67 *$ & $0,61 *$ & $-0,27$ & 0,26 & 0,28 & 0,58 \\
\hline Sagitta enflata & 0,23 & 0,18 & 0,45 & $-0,54$ & $-0,55$ & 0,79 \\
\hline Thalia democratica & $0,82 *$ & $0,83 *$ & $-0,05$ & 0,25 & 0,16 & 0,65 \\
\hline
\end{tabular}


mejante al interior de cada grupo de cruceros, pero diferente entre ellos, coincidiendo así con la agrupación obtenida con el índice de Horn (Fig. 9).

A objeto de determinar la relación existente entre las especies dominantes y los parámetros ambientales, se efectuó el análisis de correlación. En la Tabla 4 se muestran los valores de correlación obtenidos entre el In $(x+1)$ de la densidad media de cada especie versus las variables ambientales, indicándose con un asterisco los valores significativos al nivel de 0,05.

De las correlaciones obtenidas se puede decir que la densidad poblacional de $M$. atlantica está afectada positivamente por el índice de surgencia (IS), la salinidad y densidad del agua del mar; Obelia spp. es significativa sólo con IS, mostrando una relación directa con esta variable; Phialidium spp. está influenciada por los índices de surgencia y de turbulencia, y la salinidad; $S$. bierii responde en forma directa a los índices de surgencia, de turbulencia y a la estabilidad; $S$. enflata lo hace directamente con la estabilidad; y finalmente, $T$. democratica está influenciada positivamente por los índices de surgencia y de turbulencia, así como al incremento en la estabilidad de la columna de agua.

\section{DISCUSION}

Durante el período de estudio se determinó la existencia de un ciclo de temperatura superficial al interior de la bahía de Valparaíso, que tiene fluctuaciones mensuales con valores mínimos en invierno y máximos en verano. Se ha visto que los valores mensuales de temperatura superficial pueden cambiar a través de los años, e incluso en años consecutivos, debido a las variaciones propias del ambiente (Fonseca, 1987; Montecinos y Balbontín, 1993). Las mayores variaciones de salinidad se determinaron en invierno, especialmente en 1991, cuando en superficie se registraron valores inferiores a 34 psu debidos al aporte de aguas dulces del río Aconcagua.

Los valores del índice de surgencia indican que los vientos fueron moderados durante todo el año 1990 , presentando mayores magnitudes y fluctuaciones durante 1991. La alternancia entre los altos valores de este índice y los períodos de calma, son indicativos de fenómenos de surgencia. En ambos períodos anuales se observó que los mayores valores del índice de surgencia ocurrieron en primavera y verano. En este período, que se extiende por seis a siete meses, se presentaron con mayor intensidad y frecuencia los vientos del S y SW, que son más favorables para la ocurrencia de procesos de surgencia frente a la costa de Valparaíso (Pizarro, 1976; Avaria et al., 1989; Silva y Sievers, 1991; Montecinos y Balbontín, 1993). Consecuente con estas variaciones, el índice de turbulencia presentó mayores valores en primavera y verano, y menores valores en otoño e invierno.

Las características hidrográficas de las aguas de la bahía presentan una alta variabilidad, siendo afectada por las fluctuaciones de temperatura, salinidad y magnitud del viento, que pueden causar cambios en la composición específica y abundancia de plancton. De hecho, en aguas de la bahía se ha determinado que los procesos de surgencia favorecen las proliferaciones de fitoplancton con un retraso de 15 días (Avaria y Muñoz, 1982). Este retraso se debería a que el plancton vegetal requiere una mayor estabilidad de la columna de agua, para realizar sus procesos de fotosíntesis y proliferación poblacional.

La fauna macroplanctónica de las aguas de la bahía está conformada por un alto número de especies, 45 en total. Sin embargo, la comunidad estácaracterizada sólo por seis especies dominantes que en conjunto representaron el $92 \%$ del plancton total, siendo Sagitta enflata la especie más frecuente y abundante a través de todo el año. Todas estas especies se presentaron en mayor cantidad en primavera y verano, coincidiendo con la época de incremento en la temperatura y disponibilidad alimenticia en la zona. Además, de acuerdo a los resultados del análisis de correlación, los incrementos de casi todas estas especies estuvieron directamente relacionados con el índice de surgencia, proceso de alta frecuencia de ocurrencia al sur de la bahía de Valparaíso.

Los mayores incrementos poblacionales de S. enflata se registraron en enero y agosto de 1991, estando relacionados positivamente con los mayores valores de estabilidad estimados para ese mismo período. La abundancia de esta especie a través de todo el año se explicaría por el comportamiento reproductivo determinado en otras latitudes, donde puede producir sucesivas proliferaciones durante el año, causando incrementos poblacionales importantes (Alvariño, 1994). Debido a su carácter epiplanctónico y eurihalino, se distribuye ampliamente en aguas cálidas y templadas de todos los 
océanos (Fagetti, 1972; Raymont, 1983).

Por otra parte, Sagitta bierii es muy abundante a lo largo del año, y al igual que $S$. enflata presentó una elevada abundancia en enero de 1991. Este incremento en la densidad aparece directamente relacionado con los aumentos en los índices de surgencia y de turbulencia, estimados para ese mismo período. Sin embargo, en otoño e invierno de ese año, se presentó en baja cantidad en contraste con las elevadas densidades de $S$. enflata. Esta especie es de características epiplanctónicas y se distribuye principalmente en aguas del océano Pacífico Oriental, siendo señalada como endémica de aguas de la Corriente de California y de la Corriente Chile-Perú (Fagetti, 1972; Pineda, 1979).

Muggiaea atlantica es el sifonóforo más abundante en aguas de la bahía y de la costa central del país (Palma, 1977; 1994). En la bahía se presentó densidades en primavera y verano, estando correlacionada positivamente con el índice de surgencia y los mayores valores de salinidad detectados en ese período. Estos cambios de abundancia se deberían al carácter eurihalino y euritermo de esta especie (Moncaleano y Niño, 1979).

La distribución estacional de Obelia spp. y Phialidium spp. mostró aumentos de abundancia en primavera, los cuales están relacionados con su ciclo de vida meroplanctónico. Además, estos aumentos estuvieron correlacionados positivamente con el índice de surgencia, que tuvo valores máximos en este mismo período. Ambos géneros que comprenden numerosas especies, se presentan con más frecuencia en zonas costeras de aguas cálidas y templadas (Kramp, 1961).

Thalia democratica se presentó solamente de noviembre a enero formando densas agregaciones, producto de su rápido ciclo de reproducción asexuada y alta tasa de crecimiento, en concordancia con las disponibilidades de fitoplancton. Según Silver (1975), la abundancia de este organismo asociado a los máximos fitoplanctónicos, le confieren el carácter de especie oportunista. Su máximo anual registrado en enero, estuvo directamente relacionado con los índices de surgencia y de turbulencia que tuvieron altos valores en ese período. Esta especie es cosmopolita y de amplia distribución en mares cálidos y templados (Van Soest, 1975; Boltovskoy, 1980; Raymont, 1983).

Los antecedentes existentes indican que las especies mencionadas son de hábitos costeros y pue- den ocurrir en densidades elevadas, ya que pueden aprovechar las condiciones biológicas de las aguas costeras en zonas de surgencia (Pineda, 1979; Gili et al., 1987a). Además, sus densidades disminuyen drásticamente desde la costa hacia océanos abiertos (Gili et al., 1987a; Palma, 1994).

La mayor parte de las especies identificadas en aguas de la bahía de Valparaíso ha sido citada anteriormente para aguas de la costa central de Chile. Inclusive, las especies más abundantes han mantenido su preponderancia a través de los años (Avaria et al., 1989; Fagetti, 1958; 1959; Kaiser, 1993; Palma, 1977; 1994). Las especies caracterizadas como dominantes, son de carácter nerítico y también ocupan un lugar importante en otros ecosistemas costeros de aguas templadas y cálidas, tal como Obelia spp. (Riera et al., 1986); M. atlantica (Rodríguez, 1983; Riera et al., 1986; Gili et al.,1987a, 1987b; 1988); S. enflata y S. bierii (Sund, 1964; Pineda, 1979), y T. democratica (Braconnot, 1963; Silver, 1975, Raymont, 1983).

Se ha visto que las especies neríticas pueden presentar cambios drásticos en su densidad poblacional como resultado de las fluctuaciones bióticas y abióticas del ambiente. Por esta razón, las variaciones estacionales de temperatura pueden provocar cambios en la abundancia de plancton, favoreciendo la aparición de agregaciones planctónicas, particularmente en primavera y verano, cuando se encuentran las mayores disponibilidades alimenticias y ocurre la reproducción de numerosos componentes del zooplancton gelatinoso (Braconnot, 1963; Palma, 1977; 1994; Holt y Strawn, 1983; Raymont, 1983; Gili et al., 1987b; 1988).

A través de los años, se observa una constancia en la composición específica de la fauna planctónica en aguas de la costa central del país (Palma, 1977; 1994; Avaria et al., 1989). Sin embargo, se detectan cambios interanuales en la distribución temporal de algunas especies dominantes. Tal es el caso, Thalia democratica que Fagetti (1959) encontró durante todo el año en el plancton de la bahía, mientras que en la presente investigación se capturó sólo de noviembre a marzo, coincidiendo con el período más cálido del año.

A pesar de la abundancia con que se presentaron las especies dominantes en primavera y verano, fue en este período cuando se estimaron los mayores valores de diversidad. Esto fue bastante notorio en octubre, cuando se registró el mayor número de espe- 
cies durante el ciclo anual, apareciendo especies de escasa frecuencia anual, como Dipurena ophiogaster, Leukartiara octona, Halitrephes maasi, Bougainvillia involuta, Rosacea plicata, Vogtia spinosa, Sphaeronectesfragilis, Sagitta lyra, S. maxima y $S$. planctonis. La mayor parte de estos organismos tienen rangos más amplios de distribución vertical y han sido citadas para aguas más profundas (Alvariño, 1971; Fagetti, 1972; 1973; Raymont, 1983). Es probable que estas especies hayan sido transportadas a niveles superficiales por ascensos de agua ocurridos en este período, cuando el índice de surgencia alcanzó los mayores valores.

En otoño e invierno de 1991 se registró una disminución importante en la diversidad específica, cuando la comunidad planctónica estuvo dominada por el fuerte incremento en la abundancia de S. enflata, asociado a las temperaturas superficiales más elevadas que caracterizaron ese año y a la mayor estabilidad de la comuna de agua durante ese período.

La agrupación mensual de los cruceros oceanográficos en función del índice de Horn, fue bien discriminada por las variables oceanográficas, demostrándose en forma indirecta que la comunidad zooplanctónica responde a los cambios estacionales del ambiente al interior de la bahía.

El análisis espacial de la estructura comunitaria al interior de la bahía muestra la existencia de dos comunidades planctónicas que de otoño a verano de 1990 presentan variaciones en la asociación entre las estaciones del interior y del borde externo de la bahía, de acuerdo a cambios en la composición y densidad específica del macroplancton. En otoño e invierno de 1991 se observa una sola estructura producto de la dominancia numérica de Sagitta enflata. En consecuencia, es posible que la falta de un patrón que refleje los cambios en la distribución espacial de las poblaciones al interior de la bahía, podría atribuirse más a la propia heterogeneidad de los componentes zooplanctónicos, que a factores específicos del ambiente.

\section{AGRADECIMIENTOS}

Los autores agradecen a los técnicos Sres. Noé Cáceres y Reinaldo Rehhoff, así como a la tripulación del B/E «Tiberíades», por su colaboración en la obtención de las muestras zooplanctónicas. De manera especial a la Sra. Karim Kaiser por la identificación de los quetognatos.

Finalmente, nuestro agradecimiento a la Dirección General de Investigación y Postgrado de la Universidad Católica de Valparaíso, que a través del financiamiento del Proyecto DGIP/223-725, permitió la realización de esta investigación.

\section{REFERENCIAS BIBLIOGRAFICAS}

Alvariño, A. 1971. Siphonophores of the Pacific with a review of the world distribution. Bull. Scripps Inst. Oceanogr. Tech., 16, 432 pp.

Alvariño, A. 1994. Chaetognatha. In: K.G. and R.G. Adiyodi (Eds.) Reproductive Biology of Invertebrates. Vol. VI, Part B. Oxford \& IBH Publish. Co. Pvt. Lid., New Delhi, pp. 329-338.

Avaria, S. y P. Muñoz. 1982. Producción actual, biomasas y composición específica del fitoplancton de la bahía de Valparaíso en 1979. Rev. Biol. Mar., Valparaíso, 18 (2): 129-157.

Avaria, S., S. Palma, H. Sievers y N. Silva. 1989. Revisión sobre aspectos oceanográficos físicos, químicos y planctológicos de la bahía de Valparaíso y áreas adyacentes. Biol. Pesq., 18: 67-96.

Bakun, A. 1973. Coastal upwelling indices, west coast of north America, 1946-71. U.S. Department of Commerce, NOAA Technical Report, NMFSSSRS-671, 103 pp.

Bakun, A. 1975. Daily and weekly upwelling indices, west coast of north America, 1967-73. U.S. Department of Commerce, NOAA Technical Report, NMFS-SSRS-693, 113 pp.

Bodenheimer, F. 1955. Précis d'écologie animale. Payot, Paris.

Boltovskoy, E. (Ed.). 1981. Atlas del zooplancton del Atlántico Sudoccidental. Inst. Nac. Invest. Des. Pesq. (INIDEP), Mar del Plata, 936 pp.

Braconnot, J.C. 1963. Etude du cycle annuel des Salpes et Dolioles en rade de Villefranche-surMer. J. Cons., 28: 21-36.

Bravo, R. 1993. Distribución espacial y abundancia del ictioplancton en relación a las condiciones ambientales en una área de desove frente a Chile Central. Tesis para optar al grado de Master en Ciencias Biológicas mención Ecología y Sistemá- 
tica, Universidad Católica de Valparaíso, 112 pp.

Elsberry, R. y R. Garwood, Jr. 1978. Sea-surface temperature anomaly generation in relation to atmospheric storms. Bull. Amer. Meteorol. Soc., 59: 786-789.

Fagetti, E. 1958. Investigaciones sobre quetognatos colectados, especialmente, frente a la costa central y norte de Chile. Rev. Biol. Mar., Valparaíso, 8 (13): 25-82.

Fagetti, E. 1959. Salpas colectadas frente a las costas central y norte de Chile. Rev. Biol. Mar., Valparaíso, 9 (1-3): 201-228.

Fagetti, E. 1968. Quetognatos de la Expedición «MARCHILE I» con observaciones acerca del posible valor de algunas especies como indicadoras de las masas de agua frente a Chile. Rev. Biol. Mar., Valparaíso, 13 (2): 85-171.

Fagetti, E. 1972. Bathymetric distribution of chaetognaths in the south eastem Pacific Ocean. Mar. Biol., 17: 7-29.

Fagetti, E. 1973. Medusas de aguas chilenas. Rev. Biol. Mar., Valparaíso, 15 (1): 31-75.

Fonseca, T. 1981. Variabilidad de las corrientes en la bahía de Valparaíso. Invest. Mar., Valparaíso, 9 (1-2):39-60.

Fonseca, T. 1987. Anomalías de temperatura y nivel medio del mar en la costa del Pacífico sudoriental. Cienc. Tec. Mar., CONA 11: 1743.

Fonseca, T., M.A. Barbieri, S. Palma, M.I. Toledo y N. Silva. 1988. Eventos de surgencia en la zona de Val paraíso y sus efectos en el ecosistema marino. Informe Final Proyecto FONDECYT 1170/ 85.

Frontier, F. 1980. Método de análisis rápido en muestras planctónicas. Acta Oceanogr. Pacífico, INOCAR, Ecuador, 1 (1): 137-145.

Gili, J.M., F. Pages y T. Riera. 1987a. Distribución de las especies más frecuentes de sifonóforos calicóforos en la zona norte del Mediterráneo occidental. Invest. Pesq., Barcelona, 51 (3): 323-338.

Gili, J.M., F. Pages y F. Vives. 1987b. Distribution and ecology of a population of planktonic cnidarians in the westem Mediterranean. In: J. Bouillon, F. Boero, F. Cicogna and P. Cornelius
(Eds.). Modem Trends in Systematics, Ecology an Evolution of Hydroids and Hydromedusae. Oxford University Press, Oxford, pp. 150-170.

GiIi, J.M. F. Pages,A. Sabates y J. Ros. 1988. Smallscale distribution of a cnidarian population in the westem Mediterranean. 1. Plankton Res., 10 (3): 385-401.

Holt, J. y K. Strawn. 1983. Community structure of macrozooplankton in Trinity and upper Galveston Bays. Estuaries, 8 (1): 66-75.

Kramp, P. 1961. S ynopsis ofthe Medusae of the world. J. Mar. Biol. Ass. U.K., 40: 1-469.

Mackas, D. y H. Sefton. 1982. Plankton species assemblages off southern Vancouver Island: Geographic pattem and temporal variability. J. Mar. Res., 40 (4): 1173-1200.

Moncaleano, A. y L. Niño. 1979. Celentéreos planctónicos de la bahía de Cartagena, descripciones y notas ecológicas. Bull. Mus. Mar, Bogotá, 9: 37-96.

Montecinos, A. y F. Balbontín. 1993. Indices de surgencia y circulación superficial del mar: Implicancias biológicas en un área de desove de peces entre Los Vilos y Valparaíso, Chile. Rev. Biol. Mar., Valparaíso, 28 (1): 133-150.

Pages, F. y J.M. GiIi. 1992. Influence of Agulhas waters on the population structure of planktonic cnidarians in the southem Benguela Region. Sci. Mar., 56 (2-3): 109-123.

Palma, S. 1971. Descripción de Pleurobrachia pileus y Beroe cucumis (Ctenophora), encontrados frente a la costa de Valparaíso. Invest. Mar., Valparaíso, 2 (3): 41-52.

Palma, S. 1973. Contribución al estudio de los sifonóforos encontrados frente a la costa de Valparaíso. I. Taxonomía. Invest. Mar., Valparaíso, 4 (2): $17-88$.

Palma, S. 1977. Contribución al estudio de los sifonóforos encontrados frente a la costa de Valparaíso. Aspectos eco lógicos. Mem. II Simp. Latinoam. Oceanogr. Biol., Cumaná, Venezuela, vol. 2: 119-133.

Palma, S. 1986. Sifonóforos fisonectes colectados frente a Punta Curaumilla, Valparaíso. Invest. Mar., Valparaíso, 14: 69-78. 
Palma, S. 1994. Distribución del macroplancton gelatinoso en un área de desove de peces frente a la costa central de Chile $\left(32^{\circ}-33^{\circ} \mathrm{S}\right)$. Rev. Biol. Mar., Valparaíso, 29: 23-45.

Palma, S. y K. Kaiser. 1993. Plancton marino de aguas chilenas. Ediciones Universitarias de Valparaíso, Universidad Católica de Valparaíso, $151 \mathrm{pp}$.

Palma, S. y J. Meruane. 1975. Aspectos eco lógicos y crecimiento de Pleurobrachia pileus (Ctenophora) en la región de Valparaíso. Invest. Mar. Valparaíso, 6 (2): 25-40.

Pielou, E. 1969. An Introduction to Matemathical Ecology. Wiley Interscience, New York, 286 pp.

Pineda, F. 1974. Seasonal distribution of the Chaetognaths in the Bight of Panama. Bol. Inst. Oceanogr. Univ. Oriente, 18 (1-2): 65:88.

Pizarro, M. 1976. Estudios de ecología fitoplanctónica en la bahía de Valparaíso. V. Condiciones físicas y químicas del ambiente. Rev. Biol. Mar., Valparaíso, 16 (1): 35-69.

Pond, S. y G. Pickard. 1978. Introductory dynamic oceanography. Pergamon Press, 241 pp.

Purcell, P. 1985. Predation on fish eggs and larvae by pelagic cnidarians and ctenophores. Bull. Mar. Sci., 37: 739-755.

Raymont, J. 1983. Plankton and productivity in the oceans. Zooplankton. Pergamon Press, Oxford, 824 pp.

Riera, T., J. M. Gili y F. Pages. 1986. Estudio cuantitativo y estacional de dos poblaciones de cnidarios planctónicos frente a las costas de Barcelona (Mediterráneo Occidental): Ciclos entre 1966-67 y 1982-83. Misc. Zool., 10: 23-32.
Rodríguez, J. 1983. Estudio de una comunidad planctónica en el mar de Alborán. II Ciclo del zooplancton. Bol. Inst. Esp. Oceanogr., 1 (1): 1944.

Rosales, S. y F. Balbontín. 1994. Estudio de las condiciones ambientales que afectaron los períodos de desove principal de los peces pelágicos entre 1961 y 1991, entre Los Vilos y Valparaíso. Informe Final Proyecto FONDECYT 92/0531.

Sáiz, F. 1980. Experiencias en el uso de criterios de similitud en el estudio de comunidades. Arch. Biol. Med. Exp., 13: 387-402.

Silva, N. 1973. Variaciones estacionales de temperatura, salinidad y contenido de oxígeno en la zona costera de Valparaíso (septiembre 1969-agosto 1970). Invest. Mar., Valparaíso, 4 (3): 89-112.

Silva, S. y H. Sievers. 1991. Condiciones oceanográficas en el área de desove de la merluza, entre Los Vilos $\left(32^{\circ} \mathrm{S}\right)$ y Valparaíso $\left(33^{\circ} \mathrm{S}\right)$, Chile. Rev. Biol. Mar., Valparaíso, 26 (1): 109-104.

Silver, M. 1975. The habitat of Salpa fusiformis in the California Current as defined by indicator assemblages. Limnol. Oceanogr., 20 (2): 230-237.

Sund, P. 1964. The Chaetognatha of the waters of the Pero region. Bull. Int.-Am. Trop. Tuna Comm., 9: 115-165.

Sutbers, I. y K. Frank. 1990. Zooplankton biomass gradient off south-westem Nova Scotia: nearshore ctenophore predation or hydrographic separation? J. Plankton Res., 12 (4): 831-850.

Van Soest, R. 1975. Zoogeography and speciation in the Salpidae (Tunicata, Thaliacea). Beaufortia, 23 (307): 181-215.

Recibido el 9 de junio 1995.

Aceptado el 28 de agosto 1995. 